\section{Natural Dentist, natural smile}

Oraldent is pleased to announce the launch of a new range of Healthy Gums products within the popular Natural Dentist brand. Healthy Gums offers a mouth rinse and toothpaste range designed to soothe and protect bleeding, sore or swollen gums naturally, through the use of natural ingredients proven to protect the oral environment.

The mouth rinse comes in two new flavours; Refresh Mint and Orange Zest, while the toothpastes include a sodium lauryl sulphate (SLS)-free formulation that could reduce oral discomfort for sufferers of SLS induced recurrent ulcers and oral irritation. Healthy Gums products use a combination of herbal extracts and are alcohol and sugar free, making them ideal for diabetics, pregnant women and children. They have been clinically proven to be a more potent weapon

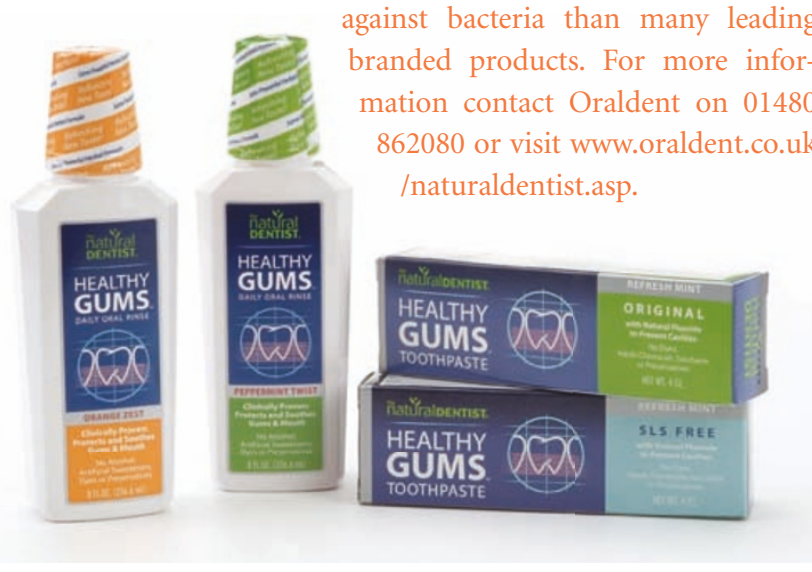

\section{Keeping staff records discreet}

Admor has launched another invaluable addition to its everexpanding range of dental stationery and administration products. The new personnel record cards act as a pocket to hold A4 documents, allowing dentists to keep important staff details in a discreet manner.

The cards are double sided, with one side providing space for personal details including change of address boxes and emergency contact details. This side also has a quick reference employment history, with details of benefit entitlements and current employment

status. The reverse of the card offers an overview of staff education and qualifications as well as details of mandatory training undertaken since their current employment.

The cards include a space for comments regarding performance reviews and outcomes of any assessments, and will file in a standard A4 storage system. For further information, please contact Admor on 01243553078 or visit www.admor.co.uk.

\section{Cabinets with a Premier pedigree}

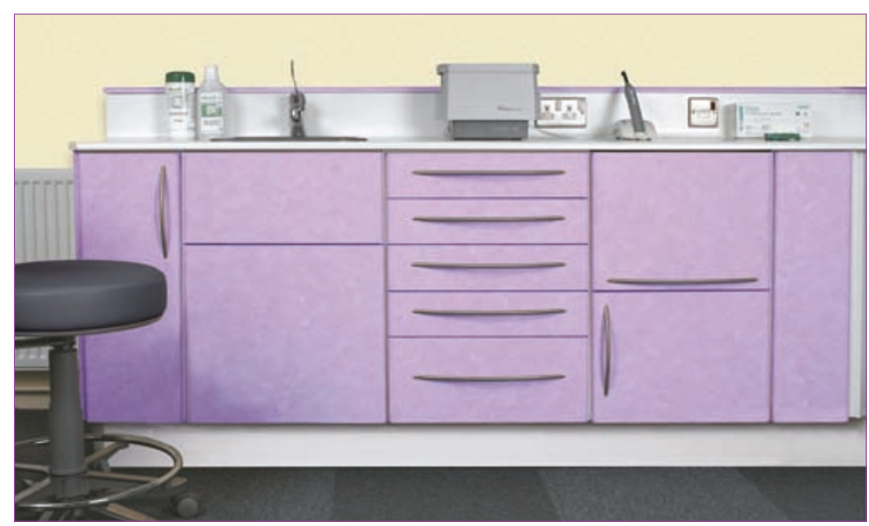

Premier Cabinets is the oldest and arguably the most prestigious name in dental cabinetry in the UK. Part of the Henry Schein Group, Premier offers three ranges of cabinets to meet your specific requirements.

The Premier Base Line is simple and practical and is available in straight runs or classical L-shape with an integrated deskwork area and upstands. Premier High Line features self-closing drawers and an almost unlimited choice of front panel design, worktop materials and colours. The drawers are unbeatable in their solidity and the finish is second to none. Finally, Premier Hygiene is a compact unit specifically designed to integrate the 'dirty area', ultrasonic bath, rinsing area, handpiece lubrication machine, autoclave and clean trays. It even has room for a fully sized floor-mounted thermo disinfection unit. For further information call Henry Schein today on 08700102041.

\section{Rapid reminders}

Are you looking for a way to send quick and easy appointment reminders? DentalText is a webbased tool designed to remind patients of impending appointments and thereby reduce costly missed appointments for your practice. By signing up to DentalText, dental professionals are able to send their patients reminders and improve patient communications simply and effectively, by

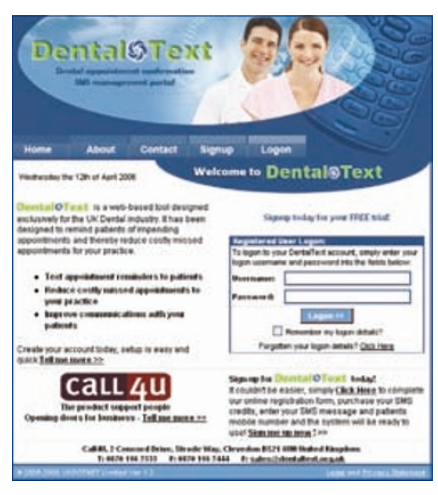
using text messages.

DentalText is easy to sign up to. Just visit www.dentaltext.org. uk, create your account and log in to type your SMS text message. Click send and the message is delivered - it's as simple as that. Messages are charged at $10 \mathrm{p}$ per text, paid for in advance, and discounts are available for high volumes of messages. For more information or a free demonstration, please call 08701162333 or email sales@dentaltext.org.uk. 